\title{
Análise descritiva de parâmetros meteorológicos como auxílio no cultivo de mamona em Diamantino/MT
}

A mamona vem se destacando como alternativa de cultivo entressafras em várias partes do Brasil devido, principalmente, a sua utilização como matéria prima de biodiesel. Mais fortemente produzida no Nordeste Brasileiro, essa cultura possui características as quais a fazem adaptar em diferentes lugares do país tupiniquim. Cidade em que se destaca fortemente nos cenários agrícolas estadual e nacional, Diamantino, presente na região da Chapada dos Parecis em Mato Grosso, é uma das principais cidades produtoras de grãos de soja no Brasil. Além da soja, a cidade também desponta como grande produtora de algodão e milho. Juntamente com o crescimento da produção agrícola, de uma maneira geral, ampliam-se os estudos de monitoramento e de descrição dos parâmetros meteorológicos importantes para o desenvolvimento dessas culturas, que servem também como auxílios para introdução de culturas não oriundas da região. Ante o exposto, este trabalho teve como objetivo avaliar, em relação à recomendação da literatura, às condições dos parâmetros meteorológicos para práticas de cultivares de mamoneira na cidade de Diamantino/MT. Para isso, realizou-se análise descritiva dos dados de temperatura do ar, precipitação e umidade relativa do ar referentes ao período de 2006 a 2015, obtidos juntos ao INMET. Obteve-se o período entre abril e setembro como o mais adequado para o cultivo de mamona na cidade, sendo os cultivares com ciclos mais curtos os mais apropriados. Os cultivares com longos ciclos, de até 250 dias, podem sofrer influência negativa dos excessos de chuva e umidade relativa.

Palavras-chave: Mamoneira; Temperatura de cultivo; Estatística descritiva.

\section{Analysis of meteorological parameters as aid in mamonal culture in Diamantino/MT}

\begin{abstract}
The castor bean has stood out as an alternative to cultivate off-season in several parts of Brazil, mainly due to its use as biodiesel feedstock. More strongly produced in the Brazilian Northeast, this culture has characteristics that make it adapt in different places from this country. A city that stands out strongly in the state and national agricultural scenarios, Diamantino, present in the region of Chapada dos Parecis in Mato Grosso, is one of the main soybean producing cities in Brazil. Besides soy, the city also emerges as a major producer of cotton and corn. Together with the growth of agricultural production, monitoring studies and a description studies of meteorological parameters relevant to the development of these crops, which also serve as aids for the introduction of crops not originating in the region, are broadened. In view of the above, this work had as objective to evaluate, in relation to the recommendation of the literature, the conditions of the meteorological parameters for practices of castor bean cultivars in the city of Diamantino-Mato Grosso. For this, a descriptive analysis of the air temperature, precipitation and air relative humidity data for the period from 2006 to 2015, obtained together with INMET was carried out. The period between April and September was the most suitable for castor bean cultivation in the city, with shorter crop cultivars being the most appropriate. Cultures with long cycles of up to 250 days may suffer a negative influence from rainfall and air relative humidity.
\end{abstract}

Keywords: Castor bean; Cultivation temperature; Descriptive statistics.

Topic: Meteorologia, Climatologia e Mudanças Climáticas

Reviewed anonymously in the process of blind peer.
Received: 14/12/2017

Approved: 24/01/2018
Luis Philippe Arruda Lima (D)

Universidade Federal de Mato Grosso, Brasil http://lattes.cnpq.br/7860864484969573 http://orcid.org/0000-0001-5906-0866

luisphilippe@fisica.ufmt.br

Kamyla Fernanda Silva Gama

Universidade Federal de Mato Grosso, Brasil

http://lattes.cnpq.br/2979113037580034

kamyllagama@hotmail.com

Lauro Leocadio Rosa

Universidade Federal de Mato Grosso, Brasil

http://lattes.cnpq.br/6296486218304982

lau.leo.ros@gmail.com
Silvino Mendes Garcia

Universidade Federal de Mato Grosso, Brasi

http://lattes.cnpq.br/3294052873036806

engmecgarcia@gmail.com

Carlo Ralph De Musis

Universidade Federal de Mato Grosso, Brasil

http://lattes.cnpq.br/2229878954372934

carlo.demusis@gmail.com

Denilton Carlos Gaio

Universidade Federal de Mato Grosso, Brasil

http://lattes.cnpq.br/8132654148436579

dcgaio@fisica.ufmt.br
Referencing this:

LIMA, L. P. A.; GAMA K. F. S.; ROSA, L. L.; GARCIA, S. M.; MUSIS C. R.; GAIO, D. C.. Análise descritiva de parâmetros meteorológicos como auxílio no cultivo de mamona em Diamantino/MT. Revista Ibero Americana de Ciências Ambientais, v.9, n.2, p.108-114, 2018. DOI: http://doi.org/10.6008/CBPC2179-6858.2018.002.0010

DOI: 10.6008/CBPC2179-6858.2018.002.0010 


\section{INTRODUÇÃO}

A produtividade agrícola causa grande impacto socioeconômico em todo o planeta, mas esses impactos resultam em números grandiosos que movimentam grande parte da economia, como é o caso do Brasil, por exemplo. Na terra tupiniquim, a produção de grãos na safra de 2015/2016 foi estimada em 210,5 milhões de toneladas com área plantada de 58,5 milhões de hectares que equivale aproximadamente 6 vezes a área total de Portugal e 226 vezes a área total de Luxemburgo, sendo 1,4\% maior que a produtividade (Kg) e 0,9\% maior que a área plantada (ha) em relação à safra de 2014/2015.

Esse crescimento faz com que se tornem mais corriqueiros na literatura a presença de estudos que possam auxiliar as práticas (FARIAS et al., 2001; PILAU et al., 2007; PEREIA, 2013; REIS et al., 2013; LEIVAS et al., 2014; BACK et al., 2014; ROMANI et al., 2016; TEIXEIRA et al, 2016; ROBLES et al., 2017). Nesse contexto, são importantes os monitoramentos temporais dos fatores agrometeorológicos que apresentam impactos sobre o crescimento e o desenvolvimento das culturas, esse monitoramento se dá normalmente por meio de análises de imagens de satélites ou por análises estatísticas dos anos anteriores do plantio, as quais são descritos os comportamentos dos fatores no período desejado e até mesmos são projetados para melhor garantia de êxito no plantio (CARAMORI et al., 2016; PAIM et al.,2017).

O Estado de Mato Grosso, situado na região centro-oeste, é considerado como uma expressão aguda da questão agrária do Brasil, pois apresenta destaque em relação a produção total do país e sua econômica também é ancorada pela produção agrícola (GIRARDI, 2016). Destaca-se nesse Estado, como objeto de estudo de fatores agrometeorológicos, a região da Chapada dos Parecis onde se encontram os municípios de Tangará da Serra, Campo Novo do Parecis e Diamantino.

Como, por exemplo, Ramos et al. (2015) estudou a precipitação pluvial em Diamantino/MT nos anos de ocorrência de El niño, La niña e Neutros caracterizando a variação da precipitação pluvial anual, mensal e decendial nesses fenômenos o que pode vir a influenciar na produção, como o caso de Berlato et al. (2005) que verificou aumento e queda de produção de milho durantes os fenômenos de El Ninõ e La Ninã, respectivamente. Dallacort et al. (2010) considerou o pinhão manso como apto às condições agroclimáticas da Região de Tangará da Serra, onde a temperatura e a precipitação estão na faixa consideradas como aceitáveis para o cultivo dessa cultura. Pertencente à mesma família vegetal, a mamoneira (Ricinus communis) surge como cultura com potencial de cultivo no Estado de Mato Grosso.

Utilizada como matéria-prima do biodiesel, a mamona tem sua principal produção e disseminação em quase todo o Nordeste, cujas condições climáticas são propícias para o seu desenvolvimento (BELTRÃO et al., 2006). Em Mato Grosso, o produtor tem-se apostado na mamona como alternativa para safrinha que significa a safra obtida entressafras por culturas de ciclos curtos. A Conab estimou que, a safra total de 2015/2016 sofreria um acréscimo de 107\% em relação à safra de 2014/2015, mas, no Nordeste, encontramse vários cultivares melhorados geneticamente que resultam em variedades diferentes da cultura. Nordestina (BRS 149), Paraguaçu (BRS 188) e BRS ENERGIA são exemplos desses cultivares que foram obtidos por meio de pesquisa da EMBRAPA (SILVA, 2007). 
Segundo Monteiro et al. (2009), a aptidão de culturas para uma determinada região pode ser analisada através de análise de temperatura e a umidade do ar, as quais influenciam diretamente o desenvolvimento e a sua produção das plantas. A temperatura afeta a respiração de manutenção, a transpiração, o repouso vegetativo, a taxa de germinação, entre outros (PEREIRA et al., 2002, MAVI et al., 2004; MONTEIRO, 2009). Já a quantidade de vapor d'água na atmosfera é um agente regulador dos ciclos das pragas e doenças nas culturas, como o oídio, por exemplo, que é uma doença que pode surgir em climas frios e úmidos, ele reduz a fotoassimilação e a produção dos cultivares (COSTAMILAN, 2002; MOREIRA et al., 2015).

Não menos importante, a precipitação afeta indiretamente o crescimento e desenvolvimento das plantas (HOOGENBOOM, 2000). Principalmente no cultivo da mamona, a altitude também deve ser levada em consideração por diversos fatores, como nebulosidade, pressão de oxigênio e pelo decréscimo da temperatura quando se aumenta a altitude (BELTRÃO et al., 2008). Ante o exposto, este trabalho teve como objetivo avaliar às condições de práticas de mamoneira para a cidade de Diamantino por meio de análise descritiva dos dados de temperatura do ar, precipitação, umidade relativa do ar, entre os anos de 2006 e 2015 e comparar com as condições de cultivo encontradas na literatura.

\section{MATERIAL E MÉTODOS}

\section{Área de estudo, tratamento de dados e dados de referências}

Distante 209 Km da capital Cuiabá, o município de Diamantino se localiza na Chapada dos Parecis, cujas coordenadas são $14^{\circ} 24^{\prime} \mathrm{S}$ de latitude, $56^{\circ} 27^{\prime} \mathrm{W}$ de longitude e altitude de $286,3 \mathrm{~m}$ (DALLACORT, 2010). A classificação de Koppen é tipo Aw, com inverno seco e verão chuvoso. Utilizou-se dados de médias mensais de temperatura e umidade relativa do ar e dados de precipitação mensal acumulada, entre os anos de 2006 e 2015, disponibilizados pelo Instituto Nacional de Meteorologia (INMET).

O tratamento estatístico se deu por meio de valores máximos e mínimos, desvio padrão e coeficiente de variação (CV). A análise do CV (\%) baseou-se na classificação de Warrick et al. (1980) que considera CV menor que $12 \%$ como baixa variabilidade, CV maior que $12 \%$ e menor que $60 \%$ como média variabilidade e CV maior que $60 \%$ como alta variabilidade.

$$
C V=\frac{S}{\bar{X}}
$$

Em que $C V$, expresso em percentagem, é o coeficiente de variação, S é o desvio-padrão e $\bar{X}$ é a média. Os cultivares de mamonas utilizados como referências neste trabalho são o Nordestina, Paraguaçu e BRS Energia, conforme recomendado por Silva (2007). As informações sobre ciclo, porte e rendimento de cada cultivar estão na Tabela 1, por essa razão, neste trabalho, utilizou-se como referência para comparação os máximos valores de cultivos os quais são denominados como longo ou curto.

As faixas de precipitação, temperatura e umidade relativa para cultivo, consideradas neste trabalho, foram de 600 a $700 \mathrm{~mm}$ de precipitação pluvial por ciclo (SILVA, 2007; MONTEIRO, 2009); $20^{\circ}$ a $38^{\circ} \mathrm{C}$ de temperatura, sendo as temperaturas em torno de $31^{\circ} \mathrm{C}$ o ideal (BREIDENBACH et al., 1974; SILVA, 2007); para 
a umidade relativa do ar os valores ideais são os próximos a 60\% (BELTRÃO et al., 2008). A faixa de altitude considerada como apropriada foi de 300 a 1500 m (SILVA, 2007).

Tabela 1: Cultivares de mamona oriundas do Nordeste brasileiro. O cultivar NORDESTINA apresenta a maior altura média e o seu ciclo longo tem duração média de até 250 dias. O cultivar BRS ENERGIA apresenta pequeno porte, pode obter um alto rendimento por hectare e é um cultivar precoce de ciclo médio de até 150 dias. O PARAGUAÇU apresenta ciclo e produtividade semelhante ao NORDESTINA, mas se difere pelo porte.

\begin{tabular}{cccc}
\hline Cultivar & Ciclo (dias) & Altura média $(\mathrm{m})$ & Rendimento \\
\hline NORDESTINA & Longo-250 & 1,9 & $1500 \mathrm{Kg}$ por hectare \\
BRS ENERGIA & Curto-150 & 1,4 & $1800 \mathrm{Kg}$ por hectare \\
PARAGUAÇU & Longo-250 & 1,6 & $1500 \mathrm{Kg}$ por hectare \\
\hline
\end{tabular}

Fonte: Silva (2007)

\section{RESULTADOS E DISCUSSÃO}

Os resultados de temperatura, umidade relativa do ar e precipitação acumulada durante período de 2006 a 2015 seguem abaixo de forma sequencial por meio da Tabela 2 e Figura 1.

Tabela 2: Dados médios, mínimos e máximos de temperaturas em cada mês, correspondente ao período de 2006 a 2015.

\begin{tabular}{|c|c|c|c|c|c|}
\hline Mês & Médio & Mínimo & Máximo & Desvio Padrão & CV (\%) \\
\hline Janeiro & 32,1 & 30,5 & 33,6 & 0,9 & $3 \%$ \\
\hline Fevereiro & 32,0 & 31,3 & 33,4 & 0,7 & $2 \%$ \\
\hline Março & 32,6 & 32,0 & 33,7 & 0,7 & $2 \%$ \\
\hline Abril & 32,7 & 31,6 & 33,5 & 0,7 & $2 \%$ \\
\hline Maio & 31,5 & 29,8 & 32,5 & 0,9 & $3 \%$ \\
\hline Junho & 32,3 & 30,6 & 33,8 & 1,0 & $3 \%$ \\
\hline Julho & 32,9 & 32,0 & 35,0 & 0,9 & $3 \%$ \\
\hline Agosto & 35,3 & 33,9 & 37,3 & 1,1 & $3 \%$ \\
\hline Setembro & 36,1 & 34,2 & 38,0 & 1,3 & $4 \%$ \\
\hline Outubro & 34,7 & 32,8 & 36,3 & 1,0 & $3 \%$ \\
\hline Novembro & 33,3 & 32,4 & 35,0 & 0,8 & $3 \%$ \\
\hline Dezembro & 32,6 & 31,8 & 34,5 & 0,8 & $3 \%$ \\
\hline
\end{tabular}

Os valores de temperatura em Diamantino no período de estudo mostrou-se estar entre a faixa de cultiva de mamona. Os maiores valores médios de temperatura foram para os meses de agosto e setembro, $35,3^{\circ} \mathrm{C}$ e $36,1^{\circ} \mathrm{C}$, respectivamente. Estando, assim, no limite da faixa de cultivo que é entre $20^{\circ}$ a 38 . Entretanto, para alguns autores deve-se tomar cuidado com temperaturas acima de $35^{\circ} \mathrm{C}$ já que acima disso as plantas apresentam redução nos processos fotossintéticos (BELTRÃO et al., 2008).

De janeiro a junho as temperaturas estiveram em torno da temperatura ideal $\left(31^{\circ} \mathrm{C}\right)$ (BREIDENBACH et al., 1974; SILVA, 2007). Em todos os meses obteve-se baixa variabilidade entre os anos (abaixo de 12\%), o que mostra a manutenção da temperatura em tornos dos valores dos anos anteriores. Essa manutenção de temperatura em torno de um valor específico é benéfica para a planta, já que uma variação abrupta da temperatura influi diretamente na fotossíntese e, consequentemente, na produção de frutos e grãos (MAGALHÃES, 1983).

Entre maio e setembro foi o período no qual houve decréscimo na umidade relativa, em relação aos outros meses (Figura 1). No mês de outubro os valores de umidade começaram a subir, devido ao início da estação chuvosa da cidade (LIMA et al., 2017), o que acaba se distanciando dos valores ideais, que é entorno de $60 \%$. Os valores de CV menores que $12 \%$ foram observados todos os meses, o que caracteriza também uma baixa variação da umidade relativa de cada mês em relação aos anos. Exceto no mês de agosto que o CV foi de $13 \%$, reportando a uma moderada variabilidade dos dados provavelmente causada pela presença 
de chuvas esporádicas que fazem com que umidade relativa volte a subir. Valores altos de umidade relativa podem afetar o padrão de floração e podem deixar as raízes atrofiadas da planta (MAZZANI, 1983).

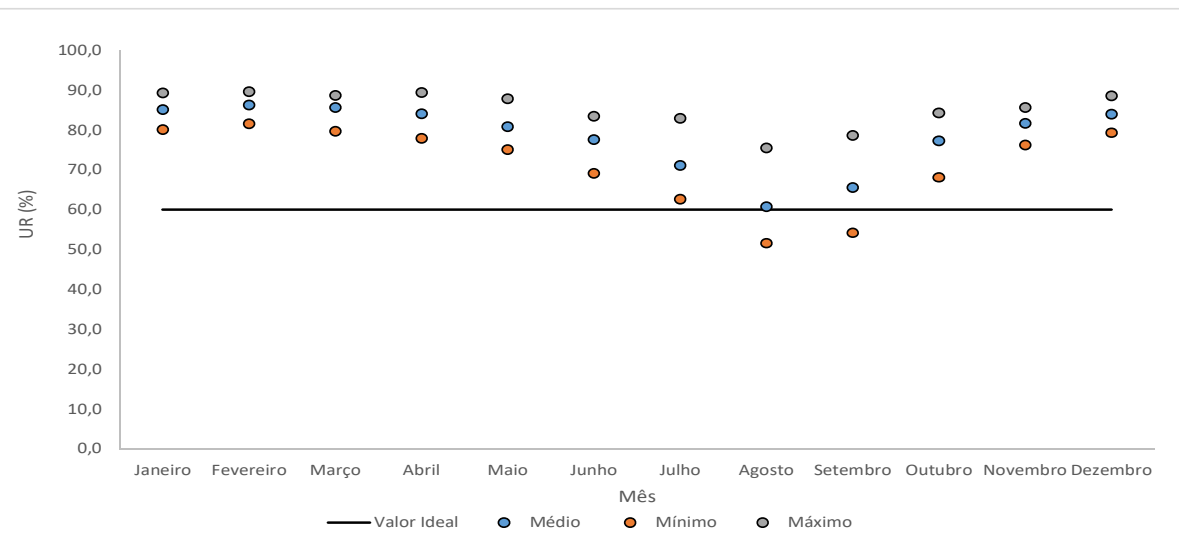

Figura 1: Umidade relativa média do ar de cada mês no período de 2006 a 2015 na cidade de Diamantino/MT. A linha escura indica o valor ideal de UR (\%) para cultivo de mamona, conforme Beltrão et al. (2008).

A precipitação pode ser considerada como um dos fatores que mais podem causar dúvidas em relação à adaptabilidade da mamona na região de Diamantino/MT (Tabela 3). As médias anuais apresentadas por Lima et al. (2017), entre 1998 e 2014, ultrapassavam os valores mínimos para o cultivo, fazendo com que os cultivares de mamona com menores ciclos de cultivo fossem de mais fácil a adaptação, como o BRS ENERGIA, com um ciclo de 150 dias. Os cultivares com ciclos longos, acima de 200 dias, como o PARAGAÇU e o NORDESTINA, são mais expostos a maiores valores de precipitação.

Tabela 3: Precipitação acumulada média mensal no período de 2006 a 2015 na cidade de Diamantino-MT. A média anual do período 2006 a 2015 foi de $1918 \pm 177,1 \mathrm{~mm}$.

\begin{tabular}{|c|c|c|c|c|c|}
\hline Mês & Médio & Mínimo & Máximo & Desvio Padrão & CV (\%) \\
\hline Janeiro & 300,4 & 94,1 & 509,0 & 139,5 & $46 \%$ \\
\hline Fevereiro & 349,5 & 192,6 & 489,5 & 104,8 & $30 \%$ \\
\hline Março & 266,3 & 165,8 & 424,8 & 81,4 & $31 \%$ \\
\hline Abril & 146,4 & 18,3 & 275,6 & 71,6 & $49 \%$ \\
\hline Maio & 46,9 & 6,4 & 172,5 & 49,8 & $106 \%$ \\
\hline Junho & 23,5 & 0,0 & 53,5 & 17,2 & $73 \%$ \\
\hline Julho & 9,4 & 0,0 & 38,6 & 15,0 & $160 \%$ \\
\hline Agosto & 16,2 & 0,0 & 97,8 & 31,2 & $192 \%$ \\
\hline Setembro & 42,3 & 0,0 & 114,0 & 38,9 & $92 \%$ \\
\hline Outubro & 210,5 & 57,7 & 314,8 & 79,7 & $38 \%$ \\
\hline Novembro & 225,5 & 67,5 & 409,9 & 91,4 & $41 \%$ \\
\hline Dezembro & 281,4 & 165,3 & 366,9 & 76,9 & $27 \%$ \\
\hline
\end{tabular}

O período para o cultivo de cultivares precoces na região, para evitar o encharcamento do solo e outros danos causados pelo estres hídrico na planta, seria mais apropriado entre os meses de abril e setembro que acumula um valor de precipitação próximo a $700 \mathrm{~mm}$, considerando os valores máximos de precipitação. Considerando os valores médios, as precipitações acumuladas se mantêm próximas de $300 \mathrm{~mm}$ que, somada a irrigação, podem-se chegar a $400 \mathrm{~mm}$, que é um valor que também pode-se obter resposta da cultura ainda com viabilidade econômica (MONTEIRO, 2009). Nesse período, exceto para abril que a variabilidade é considera moderada, tem-se coeficiente de variação CV (\%) acima de $60 \%$, isto é, alta variabilidade, devido também provavelmente há presença de chuvas esporádicas, já que nesse período temse a estação seca (LIMA et al., 2017) e nela as chuvas são mais escassas. 
A altitude em relação ao nível do mar é em torno de 280 m em Diamantino (DALLACORT, 2010; CAMACHO et al., 2012), sendo próxima do limite recomendado de 300 m (SILVA, 2007). Esse fator pode não ser considerado como limitante, pois já se obteve valores expressivos de produtividade de mamona em lugares com baixas latitudes, como no caso de Severino et al. (2006). Esses autores obtiveram para as cidades de Maranguape, 140 m de altitude, e Quixeramobim, 280 m, pertencentes ao estado Ceará, produtividades de 1682 e 1531 Kg por ha, respectivamente.

Assim, o período de abril a setembro na cidade de Diamantino apresenta potencial em ofertar as condições climáticas mais próximas do ideal para o plantio de mamona. Nesse período, além da faixa de disponibilidade hídrica no solo dada por meio da precipitação pluviométrica estar mais próximas do adequado, a umidade relativa do ar nesse período decai em relação aos restantes dos meses e entra próximo da zona ideal para o cultivo. Nesses meses, a temperatura também apresenta comportamento próximo ao limite recomendado.

\section{CONCLUSÕES}

Os fatores meteorológicos analisados neste trabalho dão aptidão, conforme a literatura, ao cultivo de mamona na cidade de Diamantino/MT entre abril e setembro. Sendo o cultivar precoce BRS ENERGIA com maior potencial de cultivo na região, pois o ciclo de cultivo é curto e evita a exposição aos grandes valores de precipitação e de umidade relativa que são ocorrentes principalmente na estação chuvosa.

Entretanto, para se confirmar a plena adaptabilidade da mamona, faz-se necessário ainda um estudo mais profundo sobre o solo para verificação de parâmetros físicos e parâmetros químicos e se há possibilidade de adequação do mesmo para introdução da cultura, caso haja necessidade. Além disso, é importante apurar a qualidade na qual os cultivares estão no decorrer e no fim do plantio, pois, dependendo do estado em que se encontra a cultura, também há possibilidade de adiantamento da colheita, vide os três cultivares citados neste trabalho, portanto, este estudo serve como auxílio para os produtores que desejam cultivar ou que já cultivam mamona e até mesmo outras culturas com comportamentos semelhantes à essa.

\section{REFERÊNCIAS}

BACK, A. J.; DELLA, B. E.; FELIPETTO, J.. Tendências nos índices climáticos e agroclimáticos aplicados à videira no Planalto Serrano de Santa Catarina. Revista Brasileira de Climatologia, v.13, 2014.

BELTRÃO, N. E. M.; OLIVEIRA, I. P. O.. Efeitos do Clima no Metabolismo Vegetal: Mamona. Campina Grande: Embrapa Algodão, 2008.

BELTRÃO, N. D. M.; ALVES, G. D. S.; LUCENA, A. M. A.; OLIVEIRA, M. I. P.. Mudanças morfofisiológicas na mamoneira cultivar BRS Nordestina em função do ambiente e do seu ciclo de vida. In: CONGRESSO BRASILEIRO DE MAMONA, 3. Anais. Campina Grande: Embrapa Algodão, 2008.
BELTRÃO, N. D. M.; CARTAXO, W. V.; PEREIRA, S. D. P.; SOARES, J. J.; SILVA, O. R. R. F.. O Cultivo sustentável da mamona no Semi-Árido brasileiro. Salvador: 2006.

BERLATO, M. A.; FARENZENA, H.; FONTANA, D. C.. Associação entre El Niño Oscilação Sul e a produtividade do milho no Estado do Rio Grande do Sul. Pesquisa Agropecuária Brasileira, v.40, n.5, p.423-432, 2005.

BREIDENBACH, R. W.; WADE, N.; LYONS, J. L.. Effect ofchilling temperatures on the activities of glyoxysomal andmitochondrial enzymes from Castor Bean seedlings. PlantPhysiology, Minneapolis, v.54, p.324-327, 1974.

CAMACHO, M. A.; NATALE, W.; BARBOSA, J. C.. Faixa de suficiência para a cultura do algodão no centro-oeste do Brasil: II. Micronutrientes. Ciência Rural, v.42, n.6, 2012. 
CARAMORI, P. H.; NITSCHE, P. R.; DEPPE, F.; LEITE, E. A.; TSUKAHARA, R. Y.; BORROZZINO, E.. Agrometeorologia operacional no estado do Paraná. Agrometeoros, v.24, n.1, 2016.

COSTAMILAN, L. M.; LINHARES, W. I.. Efetividade de genes de resistência de trigo a oídio. Fitopatologia Brasileira, v.27, p.621-625, 2002

DALLACORT, R.; MARTINS, J. A.; INOUE, M. H.; FREITAS, P. S. L.; KRAUSE, W.. Aptidão agroclimática do pinhão manso na região de Tangará da Serra/MT. Revista Ciência Agronômica, v.41, n.3, p.373-379, 2010.

FARIAS, J. R. B.; ASSAD, E. D.; ALMEIDA, I. R.; EVANGELISTA, B.A.; LAZZAROTTO, C.; NEUMAIER, N.; NEPOMUCENO, A. L.. Caracterização de risco de déficit hídrico nas regiões produtoras de soja no Brasil. Revista Brasileira de Agrometeorologia, Passo Fundo, v.9, n.3, p.415-421, 2001.

GIRARDI, E. P.. Mato Grosso: expressão aguda da questão agrária brasileira. Confins: Revista Franco-Brasilera de Geografia, n.27, 2016.

HOOGENBOOM, G.. Contribution of agrometeorology to the simulation of crop production and its application. Agricultural and Forest Meteorology, n.103, p.137-157, 2000.

LEIVAS, J. F.; ANDRADE, R. G.; VICTORIA, D. C.; TORRESAN, F. E.; VICENTE, L. E.; TEIXEIRA, A. H. C.; BOLFE, E. L.; BARROS, T. R.. Avaliação do índice de vegetação padronizado no monitoramento indicativo de estiagens em períodos críticos da soja no Sul do Brasil. Revista Brasileira de Cartografia, v.5, n.66, p.1145-1155, 2014.

LIMA, L. P. A.; ROSA, L. L.; GARCIA, S. M.; MUSIS, C. R.; GAIO, D. C.. Análise descritiva e comparação de curvas de precipitação em Diamantino, Mato Grosso. Revista IberoAmericana de Ciências Ambientais, v.8, n.3, 2017.

MAVI, H. S.; TUPPER, G. J.. Agrometeorology: Principles and application of climate studies in agriculture. New York: Food Products Press, 2004.

MONTEIRO, J. E. B. A.. Agrometeorologia dos cultivos: o fator meteorológico na produção agrícola. Brasília, DF: INMET, 2009.

MOREIRA, P. S. P.; DALLACORT, R.; GALVANIN, E. A. S.; NEVES, R. J.; CARVALHO, M. A. C.; BARBIERI, J. D.. Ciclo diário de variáveis meteorológicas nos biomas do estado de mato grosso (meteorological variables daily cycle in mato grosso state biomes). Revista Brasileira de Climatologia, v.17, n.11, p.2237-8642, 2015

PEREIRA, A. R.; ANGELOCCI, L. R.; SENTELHAS, P. C.. Agrometeorologia: fundamentos e aplicações práticas. Guaíba: Agropecuária, 2002.

MAGALHÃES, A. C. N.. Fotossíntese. In: FERRI, M. G.. Fisiologia Vegetal 1. São Paulo: Pedagógica e Universitária, 1983. p.117-166.
MAZZANI, B.. Cultivo y melhoramiento de plantas oleaginosas. Caracas: Centro Nacional de Investigaciones Agropecuárias. 1983.

PAIM, P. F. E.; GALAFASSI, C.; DE CARVALHO, J. O.; ROMANI, C.; NOGUEIRA, J. G. R.. Estação de Monitoramento de Temperatura e Umidade Relativa do Ar Automática. Anais do Salão Internacional de Ensino, Pesquisa e Extensão, v.8, n.2, 2017

PEREIRA, G. E.. Os vinhos tropicais em desenvolvimento no Nordeste do Brasil. Com Ciência, Campinas, n.149, p.1-3, junho, 2013.

PILAU, G. P.; ANGELOCCI, L. R.; SCARPARI FILHO, J. A.. Balanço de radiação de uma laranjeira em pomar e sua relação com radiação solar global e com saldo de radiação de gramado. Revista Brasileira de Agrometeorologia, Santa Maria, v.15, n.3, p.257-266, 2007.

RAMOS, H.; DALLACORT, R.; SANTI, A.; JUNIOR, S.; QUEIROZ, T.. Pluvial precipitation in el niño, la niña and neutral years in diamantino/MT. Revista Brasileira de Meteorologia, v.30, n.1, p.71-80, 2015

REIS, L. S.; AZEVEDO C. A. V.; ALBUQUERQUE, A. W.; JUNIOR J. F. S.. Índice de área foliar e produtividade do tomate sob condições de ambiente protegido. Revista Brasileira de Engenharia Agrícola e Ambiental, v.17, n.4, p.386-391, 2013.

ROBLES, J. M.; BOTÍA, P.; PÉREZ-PÉREZ, J. G.. Sour Orange rootstock increases water productivity in deficit irrigated 'Viena' lemon trees compared with Citrus macrophylla. Agricultural Water Mangement, v.186, p.98-107, 2017.

ROMANI, L. A. S.; BAMBINI, M. D.; COLTRI, P. P.; JUNIOR, A. L.; KOENIGKAN, L. V.; OTAVIAN, A. F.; ASSAD, E. D.. Sistema de Monitoramento Agrometeorológico-Agritempo: inovação em rede apoiando políticas públicas e a tomada de decisão agrícola. Agrometeoros, v.24, n.1, 2016.

SEVERINO, L. S.; MILANI, M.; MORAES, C. R. de A.; GONDIM, T. M. de S.; CARDOSO, G. D.. Avaliação da produtividade e teor de óleo de dez genótipos de mamoneira cultivados em altitude inferior a 300 metros. Revista Ciência Agronômica, Fortaleza, v.37, n.2, p.188-194, 2006.

SILVA, V.. A cultura da mamona. Fortaleza: Secretaria de Desenvolvimento Agrário do Ceará, 2007.

TEIXEIRA, A. H. C.; LEIVAS, J. F.; SILVA, G. B.. Options for using Landsat and RapidEye satellite images aiming the water productivity assessments in mixed agro-ecosystems. Proceedings of SPIE, v.9998, p.99980A-1-99980A-11, 2016.

WARRICK, A. W.; NIELSEN, D. R.. Spatial variability of soil physical properties in the field. In: HILLEL, D.. Applications of soil physics. New York: Academic Press. 1980, p.350.

A CBPC - Companhia Brasileira de Produção Científica (CNPJ: 11.221.422/0001-03) detém os direitos materiais desta publicação. Os direitos referem-se à publicação do trabalho em qualquer parte do mundo, incluindo os direitos às renovações, expansões e disseminações da contribuição, bem como outros direitos subsidiários. Todos os trabalhos publicados eletronicamente poderão posteriormente ser publicados em coletâneas impressas sob coordenação da Sustenere Publishing, da Companhia Brasileira de Produção Científica e seus parceiros autorizados. Os (as) autores (as) preservam os direitos autorais, mas não têm permissão para a publicação da contribuição em outro meio, impresso ou digital, em português ou em tradução. 